\title{
BMJ Open Patient motives behind low-acuity visits to the emergency department in Germany: a qualitative study comparing urban and rural sites
}

\author{
Martina Schmiedhofer, Martin Möckel, Anna Slagman, Johann Frick, \\ Stephan Ruhla, Julia Searle
}

To cite: Schmiedhofer M, Möckel M, Slagman A, et al. Patient motives behind lowacuity visits to the emergency department in Germany: a qualitative study comparing urban and rural sites. BMJ Open 2016:6:e013323. doi:10.1136/bmjopen-2016013323

- Prepublication history and additional material is available. To view please visit the journal (http://dx.doi.org/ 10.1136/bmjopen-2016013323).

Received 11 July 2016 Revised 3 October 2016 Accepted 19 October 2016

CrossMark

Division of Emergency Medicine, Campus Virchow Klinikum (CVK) and Campus Charité Mitte (CCM), Charité —Universitätsmedizin Berlin, Berlin, Germany

\section{Correspondence to} Martina Schmiedhofer; martina.schmiedhofer@ charite.de

\section{ABSTRACT}

Objectives: The increasing number of low-acuity visits to emergency departments (ED) is an important issue in Germany, despite the fact that all costs of inpatient and outpatient treatment are covered by mandatory health insurance. We aimed to explore the motives of patients categorised with low-acuity conditions for visiting an ED.

Methods: We conducted a qualitative study in two urban and one rural ED. We recruited a purposive sample of adults, who were assigned to the lowest two categories in the Manchester triage system. One-to-one interviews took place in the ED during patients' waiting time for treatment. Interview transcripts were analysed using the qualitative data management software MAXQDA. A qualitative content analysis approach was taken to identify motives and to compare the rural with the urban sites.

Results: A total of 86 patients were asked to participate; of these, $\mathrm{n}=15$ declined participation and $n=7$ were excluded because they were admitted as inpatients, leaving a final sample of 40 female and 24 male patients. We identified three pathways leading to an ED visit: (1) without primary care contact, (2) after unsuccessful attempts to see a resident specialist or general practitioner (GP) and (3) recommendation to visit the ED by an outpatient provider. The two essential motives were (1) convenience and (2) health anxiety, triggered by time constraints and focused usage of multidisciplinary medical care in a highly equipped setting. All participants from the rural region were connected to a GP, whom they saw more or less regularly, while more interviewees from the urban site did not have a permanent GP. Still, motives to visit the ED were in general the same.

Conclusions: We conclude that the ED plays a pivotal role in ambulatory acute care which needs to be recognised for adequate resource allocation.

Trial registration number: DRK S00006053

\section{INTRODUCTION}

The increasing number of visits to emergency department (ED) by patients with acute, but

\section{Strengths and limitations of this study}

- This study explored patients' motives for seeking care in an emergency department in a real-life context.

- We covered different perspectives by investigating two regions with different sample populations.

- We used a qualitative content analysis method, which works both inductively and deductively and furthermore allows tracking data collection and inspection of research findings in a transparent way.

- Qualitative analysis is subjective by nature and researcher bias cannot be completely excluded.

- The extent of variations within this study is limited and may not be generalisable to all other settings.

low-acuity conditions is an increasing and important issue in Germany. Like in many other countries, these patients contribute to ED crowding, which has been associated with negative effects on clinical outcomes. ${ }^{12}$ Even though crowding is reported throughout Germany, there is little evidence about what the underlying rationale of the increased usage by patients without 'classic emergencies' is. Health insurance is obligatory for all citizens registered in Germany and, unlike countries with insurance-related healthcare barriers, ${ }^{3}$ the German healthcare system covers all costs of both inpatient and outpatient treatment, including medication. Patients are free to choose any doctor they would like to see, including specialists. Therefore, the decision to seek care in an ED must be mainly driven by motives other than financial considerations. Current hypotheses on patient motivations range from insufficient provision of outpatient healthcare to subjective changes in demand behaviour. ${ }^{4}$ 
ED visits with conditions that could be managed and treated in the primary care system impact the separation between the outpatient and inpatient sectors, which is intrinsic for the German healthcare system; hospital care is meant to be strictly limited to inpatient treatment, while resident specialists and GPs have to guarantee outpatient care. Consequently, the healthcare budget is also strictly separated between healthcare providers for inpatient and outpatient care. The budgets of both sectors are negotiated between the Federal Association of Sickness Funds and the Federal associations of inpatient and outpatient service providers, respectively. In the current system, ambulatory care in the EDs is largely underfunded $;{ }^{5}$ the increasing shift of patients from the outpatient sector to EDs has led to a controversial debate between healthcare policymakers and representatives of inpatient and outpatient healthcare providers about insufficient service provision by GPs and resident specialists, as well as a demand for redistribution of outpatient budgets. ${ }^{56}$

Against this background, a deeper knowledge of patients' rationale for using the EDs with low-acuity conditions is essential for developing policy responses and solutions to the changing structure of healthcare demand. Current evidence about low-acuity ED visits was mainly generated in different healthcare systems, many of which have unequal access to health services. Hence, the results can only be transferred to Germany to a limited degree. Our research aim was to explore the motivation of patients categorised as low-acuity for visiting the ED. The objective was to include a broad range of reasons from patients living in different environmental settings. Furthermore, we aimed to contribute a German perspective to the international research of ED usage with low urgency.

\section{METHODS}

\section{Study design}

We conducted a qualitative study with semistructured, face-to-face interviews to assess participants' behaviour and attitudes. ${ }^{78}$

The geographical density of GPs and Specialists in Germany greatly differs between urban and rural areas, and in rural areas access by public transport to medical care providers is limited. Since this might affect the reasons for ED usage with minor conditions, we enrolled a purposive sample of patients in highly structured urban and rural regions with low population density, to capture a broad range of motives.

Between April 2014 and April 2015, one of the authors (MS) conducted patient interviews at three EDs, two of which are units of a tertiary care hospital in the centre of Berlin. One of these EDs (Urban Site I) is located in a catchment area with lower socioeconomic status while the other (Urban Site II) is located in the heart of the Berlin government quarter. ${ }^{9}$ The third ED (Rural Site) is located in a city with 50000 inhabitants in a rural region in Saxony-Anhalt, a state of former socialist Germany. The catchment area of the rural ED covers a radius of $\sim 30 \mathrm{kms}$. In all three sites, the majority of low-acuity visits occur during office hours of outpatient care providers (figures 1 and 2).

\section{Study setting and population}

We recruited adult patients categorised as Manchester Triage System (MTS) categories four and five, the lowest in terms of treatment acuity. Patients who were admitted as inpatients either directly from the ED or within 30 days after their ED visit were excluded from the analysis.

Eligible patients were approached by the interviewer either in the waiting area or in the triage room. All participants gave written informed consent.

Interviews took place in a separate room of the ED facilities and were audio taped and then transcribed verbatim. Data collection was conducted from Monday to Sunday, early in the morning to late evening at each ED, until all weekdays were covered once and thematic saturation was reached. Following each interview, field notes were taken to document impressions on atmosphere, non-verbal communication and special features during the interview.

New findings ended after 23 interviews at Urban Site I and after 17 interviews at Urban Site II. At the Rural Site, we conducted a total of 31 interviews.

\section{Interview}

To identify a broad range of motives, we used a semistructured interview guide with open-ended questions (box 1, original German interview guide in see online supplementary material). The content was reviewed by the multidisciplinary research group of the ED (MS, JS, AS, MM including two physicians, one epidemiologist, one sociologist/MPH and one MPH) and was modified after the first two interviews.

\section{Data analysis}

All interview transcripts and field notes were entered into the qualitative data management software MAXQDA and anonymised for analysis. We took a qualitative content analysis (QCA) approach to identify patient motives, using a multistage process. QCA works equally coding inductively and deductively into themes emerging from text analysis; data can be used to form a theory, as well as to test assumptions. Furthermore, tracking of data collection and analysis allows inspection of the research process and result findings. ${ }^{10}$ To answer the research question, one of the authors (MS) first reviewed the transcripts and coded them line by line. In the next step, the coding was revised by a second author (JS). Sentence chunks or single words were labelled independently with broad categorisation, mainly focusing on the interview guide. Material was carefully re-read and completely recoded as new reasons emerged (MS and JS). Moreover, coding consistency was further 
Figure 1 Daily curves for patient visits to the ED for urban study colours reflect the triage categories assigned to the ED patients as used in the Manchester Triage System (MTS): 1 (red): immediately (only discharged after ambulant treatment, eg, with eye injury or presenting with strong pain); 2 (orange): very urgent (10 $\mathrm{min}) ; 3$ (yellow): urgent (30 $\mathrm{min}) ; 4$ (green): normal demand (90 min); 5 (blue): non-urgent demand department. sites I and II. The different a few patients in category 1 were (120 min). ED, emergency

Daily curve N=43.323 outpatients in MTS-categories Jan 2014 - Dec 2014 Urban region, Site I and II

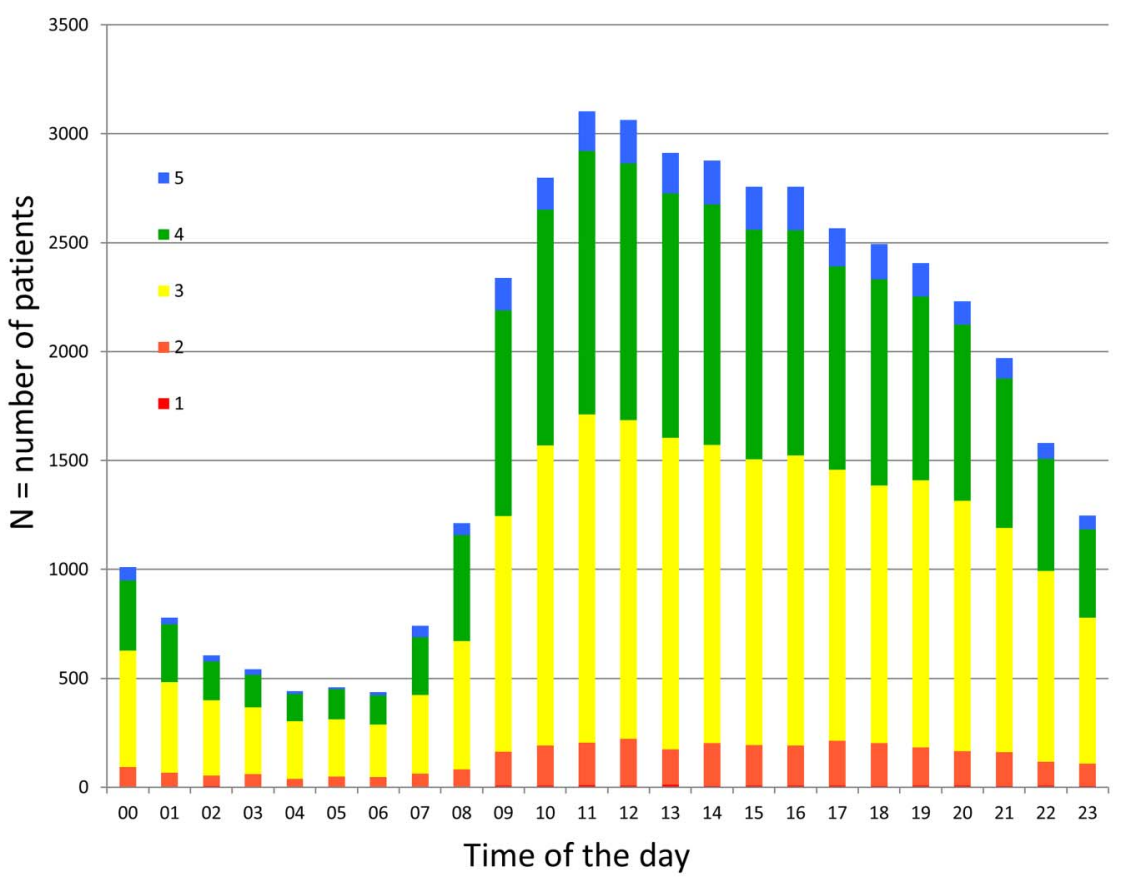

Daily curve $\mathrm{N}=17,356$ outpatients in MTS-categories March 2015 - February 2016

visits to the ED for the rural study site. The different colours reflect the triage categories assigned to the ED patients as used in the Manchester Triage System (MTS): 1 (red): immediately (only a few patients in category 1 were discharged after ambulant treatment, eg, with eye injury or presenting with strong pain); 2 (orange): very urgent (10 min); 3 (yellow): urgent (30 min); 4 (green): normal demand (90 min); 5 (blue): non-urgent demand (120 min). ED, emergency department. Rural Site

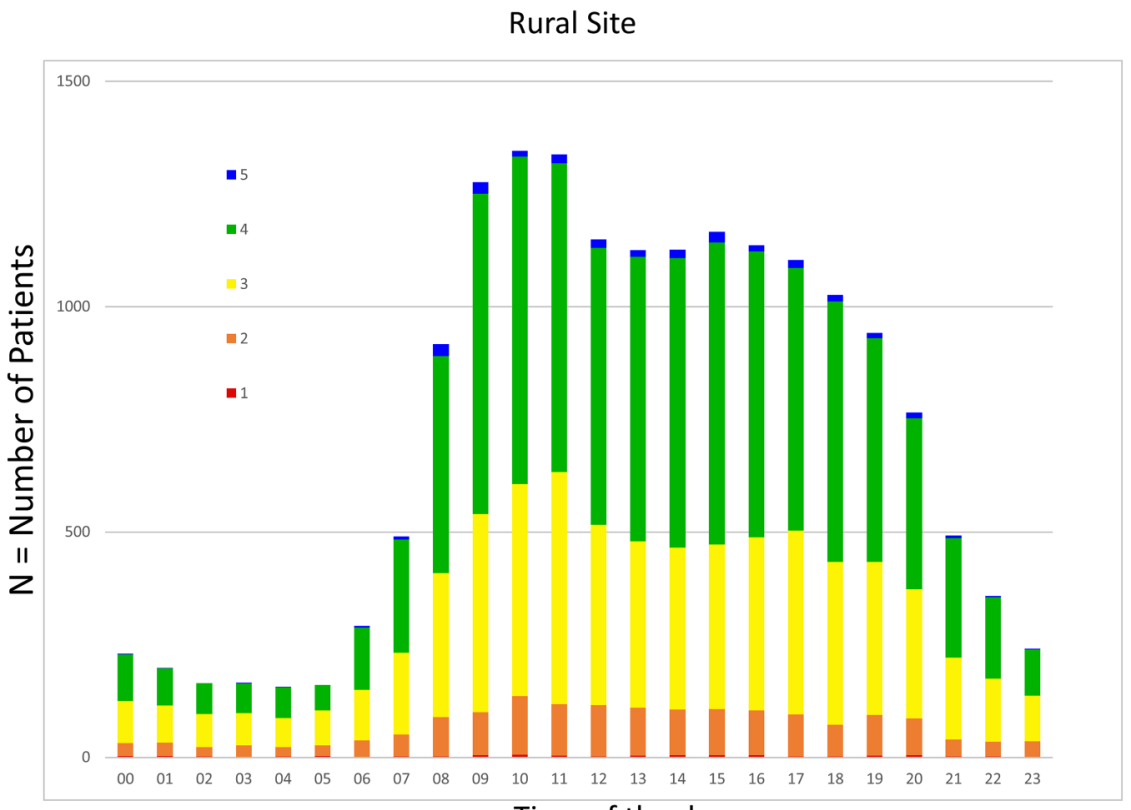

Time of the day cochecked by two authors (AS and JF). In subsequent discussions, four authors (MS, JS, AS and JF) of the multidisciplinary research group refined the final coding structure. Based on this structure, subgroups of behavioural patterns and attitudes were compared and contrasted to gain powerful conclusions. Finally, the main types of motives were developed, which are applied to all categories identified in our sample to answer the research question.

\section{RESULTS}

\section{Patient characteristics}

We approached 86 patients who met the inclusion criteria, of whom 15 declined to participate. Theme saturation was reached after interviewing 71 patients at the 3 participating EDs. Seven participants were excluded from the analysis due to hospital admission within 30 days after the interview, leaving a final sample of 64 patients (40 female and 24 male). The demographic 
Box 1 Guide for the semistructured interviews. Questions were adapted to the requirements of the individual interviews

Please describe to me what made you visit the emergency department (ED) today.

Since when have you had these symptoms? Exactly when did they start?

When did you decide to see a doctor?

What did you do next? (Waiting, trying to make an appointment with a general practitioner (GP) or Specialist, direct visit to the ED?)

Do you have a GP or resident specialist (RS) you regularly go to? Did you contact him/her before you came to the ED?

How would you describe your confidence in your GP or RS?

What do you usually do when you feel sick?

Do you live with a partner?

Do you live with children?

Are you employed? (If yes, what kind of profession do you have? Do you work full-time or part-time?)

Do your working hours and/or childcare impact your choice of healthcare provider?

characteristics of the participants are outlined in table 1. (Most frequent International Classification of Disease 10th Edition codes assigned to the study participants during their ED visit are presented in the see online supplementary material).

\section{Motives for visiting the ED}

Our data interpretation followed patients' narratives from the onset of symptoms through the decision to require medical treatment and the ED visit. We identified three 'pathways' participants took to visit the ED: (1) a direct visit to the ED, (2) a visit to the ED after unsuccessful attempts to see a doctor in the outpatient system and (3) a visit to the ED after recommendation from an outpatient doctor to do so. At first sight, the pathways seem to cover distinctive patient groups, but deeper analysis revealed two recurring main motives applicable in all three pathways: (1) convenience and (2) health anxiety. This theoretical framework for low-acuity visits to the ED is outlined in figure 3. Meaningful quotes are presented in table 2 (Original German quotes are presented in see online supplementary material).

\section{Pathways A and B}

Patients without any preceding attempt to see a resident specialist or GP were classified into pathway A, and those who tried but failed to make an appointment with a GP or resident specialist before coming to the ED into pathway B. However, the time span between the onset of symptoms, the decision to get medical treatment and the ED visit as well as the efforts made to see an outpatient doctor reveals ambiguities between decision-making and acting. Therefore, in a deeper level of analysis, patient motives overlap between the different pathways. We report patient motives in the pathways most frequently used. Corresponding quotes representative of the different subgroups can be found in table 2.

\section{Pathway A: direct visit to the ED}

Subgroup A1 'doc to go': convenience driven visit to the ED We labelled subgroup 1 'doc to go', because patients perceived a spontaneous visit at any time to see a doctor in the ED as more convenient than undergoing a scheduled appointment with an outpatient provider, even though they had to spend several hours waiting. The subgroup mainly consisted of younger, healthier and busier patients. Some of the urban participants neither had a GP nor considered it necessary to have one. Other interviewees explicitly underlined the importance of finishing work prior to a doctor's visit and therefore

Table 1 Demographic characteristics of the study participants

\begin{tabular}{llllll}
\hline & $\begin{array}{l}\text { Urban } \\
\mathbf{N = 3 9}\end{array}$ & $\begin{array}{l}\text { Rural } \\
\mathbf{N = 2 5}\end{array}$ & $\begin{array}{l}\text { Female } \\
\mathbf{N = 4 0}\end{array}$ & $\begin{array}{l}\text { Male } \\
\mathbf{N = 2 4}\end{array}$ & $\begin{array}{l}\text { All } \\
\mathbf{N = 6 4}\end{array}$ \\
\hline Age (mean) & 39 & 44 & 37.5 & 46.0 & 41 \\
Min-max & $18-77$ & $18-81$ & $18-81$ & $22-74$ & $18-81$ \\
$\quad$ Median & 39 & 49 & 37.5 & 49 & 40 \\
German $(n(\%))$ & $28(69 \%)$ & $24(96 \%)$ & $34(85 \%)$ & $18(75 \%)$ & $52(81 \%)$ \\
Migrant & $11(31 \%)$ & $1(4 \%)$ & $6(15 \%)$ & $6(25 \%)$ & $12(19 \%)$ \\
EU & $2(8 \%)$ & $1(4 \%)$ & $1(2.5 \%)$ & $2(8 \%)$ & $3(5 \%)$ \\
Turkey & $7(18 \%)$ & 0 & $3(7.5 \%)$ & $4(17 \%)$ & $7(11 \%)$ \\
Other & $2(5 \%)$ & 0 & $2(5 \%)$ & 0 & $2(3 \%)$ \\
Occupational status & & & & & $30(47 \%)$ \\
Employed $(\mathrm{n}(\%))$ & $18(46 \%)$ & $12(48 \%)$ & $18(45 \%)$ & $12(50 \%)$ & $9(14 \%)$ \\
Self-employed (n (\%)) & $7(18 \%)$ & $2(8 \%)$ & $4(10 \%)$ & $5(21 \%)$ & $12(19 \%)$ \\
In education (n (\%)) & $8(20 \%)$ & $4(16 \%)$ & $10(25 \%)$ & $2(8 \%)$ & $9(14 \%)$ \\
Pensioner $(\mathrm{n}(\%))$ & $3(8 \%)$ & $6(24 \%)$ & $5(12.5 \%)$ & $4(17 \%)$ & $4(6 \%)$ \\
Job-seeker/unemployed $(\mathrm{n}(\%))$ & $3(8 \%)$ & $1(4 \%)$ & $3(7.5)$ & $1(4 \%)$ & \\
\hline
\end{tabular}

${ }^{*}$ The origin of migrants is identified by non-German citizenship and/or the place of birth abroad.

EU, European Union; Max, maximum; Min, minimum. 
Figure 3 Conceptional

framework identified from our sample through content analysis.

It needs to be noted that the motives of resident physicians to advise patients to visit an ED were also reported by the patients and not directly by the physicians. $E D$, emergency department.

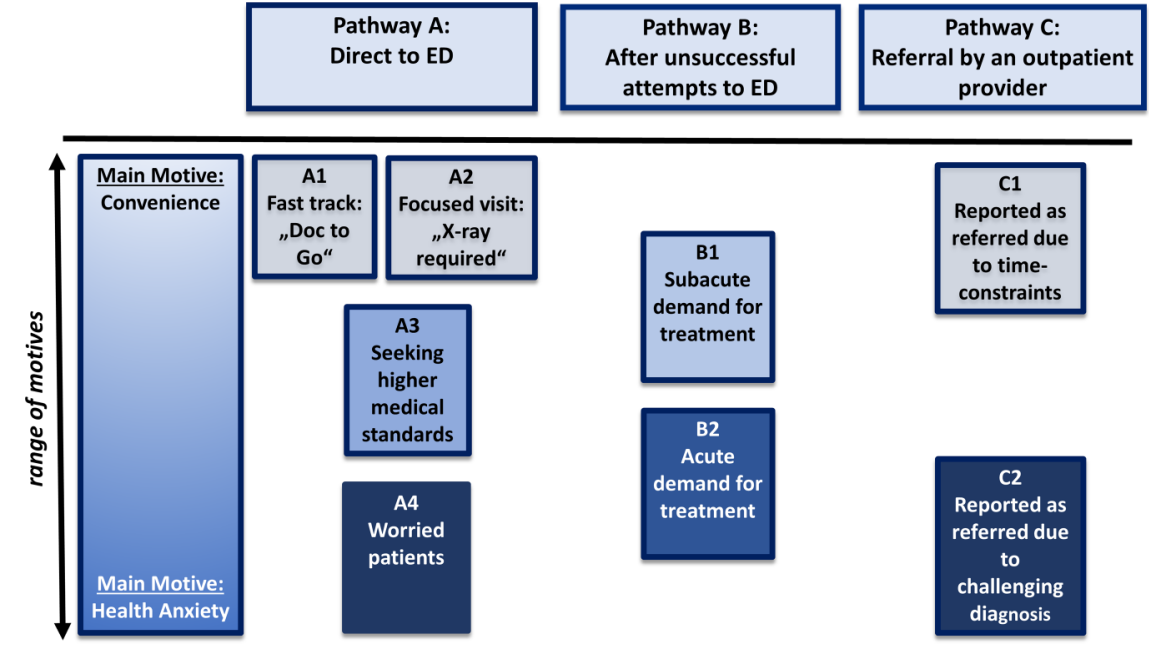

Pathway A: Direct to ED

complementary source of care, while others stressed the availability of treatment from several specialists during a single visit as very comfortable. For this subgroup, from rural and urban sites, anxiety about health status as well as convenience reasons led to the $\mathrm{ED}$ visit. In this context, it has to be noted that accessibility to specialist care was lower in the rural area.

\section{Subgroup A4: worried patients: anxiety-driven visits}

A fourth subgroup (4) of all ages and from rural and urban areas consisted of worried patients, who reported fear and uncertainty about their health status impairing their quality of life. In urban areas, many of the migrants were assigned to this subgroup. Many of these patients had been on an odyssey from doctor to doctor and addressed the ED after their symptoms failed to improve, as well as the return of symptoms or undiagnosed physical symptoms. Some of these patients seemed to be trapped within a diagnostic circle. Meaningful quotes representative for all subgroups are presented in table $2 \mathrm{~A}$.

\section{Pathway B: ED visit after unsuccessful attempts to see a GP or resident specialist}

About half of our participants reported unsuccessful attempts to consult a GP or resident specialist before visiting the ED. While subgroup B1 tried to see a resident specialist or GP in the short term for a condition they perceived as acute or urgent, subgroup B2 failed to get an appointment with a resident specialist in the short or medium term. However, deeper analysis revealed varying efforts in seeing a doctor. While some patients reported extended endeavours to make an appointment with a GP or resident specialist, others stated having made only one or two phone calls prior to the ED visit. Furthermore, the reported time span between the onset of symptoms and the ED visit ranges from a few hours to several weeks. Even patients who felt a need for urgent treatment finished their assignments at work before attempting to see a doctor. As a result, they had to visit the ED because the GP or Specialist's 


\section{(A) Pathway A: direct to the ED}

\section{Subgroup $A 1$ \\ 'doc to go' \\ "Well, it's the extreme waiting times at the GP, or all that. It's} something I just can't do. So, when I have something urgent then I usually go to the hospital and when it isn't so urgent, I just treat myself a bit" (P09U)

"Well, I simply can't do between 9.30 and 7 o'clock in the evening, anything medical" (P27U)

"I'm self-employed and always have to go to work. I don't have time to sit down in a doctor's waiting room. That's too stressful for me. To sit around for so long and nothing comes out of it" (P26R).

"No, I don't have one (GP). I don't really go/I don't get ill. But I should go some time, haha, and I guess I should have a GP, but then I always forget, but I should be doing it" (P26U).

\section{B) Pathway B: visiting ED after an unsuccessful attempt to see a resident doctor}

\section{Subgroup B1: subacute demand for treatment}

Subgroup A2

Focused visit: X-ray required

"Before I go to the GP, I don't think he is even open today, I have to wait until tomorrow and then he's only open between 4 and 6 , then I get there, have to wait around, and they then only give you a referral to a surgeon or an X-ray department and then this is probably a quicker way, I think" (P3R)

And your GP can't do it?

"No, because X-ray is needed and everything" (P12R)

"I've twisted my ankle and that needs X-ray, I suppose, probably" (P8R).

"Then you go straight away to the ED, such a case, because GP can't do much, because he has no X-ray at hand" (P7R).

\section{Subgroup A3}

Seeking higher medical standards

Subgroup A4

"And I always feel that the hospital safer, there are many more possibilities, the GP is too limited to little things, but taking blood sample doesn't work, will take 2 or 3 days, for example. Or urine, urine is a bit quicker, I mean than taking blood, but here it takes an hour, and all is done, blood, urine everything"(P40U).

"I'm here with my heart condition and came here for other things as well, I like it here, feel looked after, because I had a deep thrombosis, and then I went to another hospital, and they made me look as if I was just faking it” (P3U).

"Then I tried to find an orthopedic surgeon here in this area, no chance, you've got no chance. Phoning them doesn't

work, they just tell you, they can give you an appointment in 4 months" (P19R).

"The doctor looked at the blood test and said: that all has to be analyzed more thoroughly and he referred me. Then I

called lot of docs and was given appointments from between 3 and 5 months from now. I'm worried about the problem, more and more, day by day (...) It just took too long and then I thought, I just come here. Maybe l'll get a check-up and then I get the results and know what to do next" (P18U).

\section{Subgroup B2: acute demand fo}

\section{treatment}

"I tried to see some kind of a GP or surgeon, but the next appointments were in a month time, I mean I've definitely got one, let's say a whole network of doctors but none who would have been able to do it straight away. So I tried, but it just didn't work out" (P27U). "Yeah, on Saturday I had a little accident - got stuck in the back of my hand, stuck in the thorns, they tore into me and I didn't manage to get them all out. Now my whole hand is swollen up. That's why I ended up going to the surgeon this morning, one l've never been to-the waiting room was packed saw it straight away and him from reception told me, the earliest I could get
"Yeah, and they gave me a jab, well the GP did, and l'd say, you know, the injections they do here, are not the same as the ones, you know, here at

the ED and then, there's a surgeon here, probably, who does it and I reckon it's going to be a bit more professional, like, and l've heard they have different gear here, that the medicines what they inject, are, let's say, more effective" (TN 29R). "It's only psyche and nothing more and I shouldn't exaggerate and then he had realized that is was actually worse and then had I, and then I immediately said I would like a referral to (Place of ED) and then I had gotten it and now I'm sitting here" (P20R).

"I already told him (GP) about my problem but he said it wasn't anything and that's why l'm here, now" (P20U). 
Table 2 Continued

\begin{tabular}{|c|c|c|c|}
\hline \multicolumn{4}{|l|}{ (A) Pathway A: direct to the ED } \\
\hline $\begin{array}{l}\text { Subgroup A1 } \\
\text { 'doc to go' }\end{array}$ & $\begin{array}{l}\text { Subgroup A2 } \\
\text { Focused visit: X-ray required }\end{array}$ & $\begin{array}{l}\text { Subgroup A3 } \\
\text { Seeking higher medical standards }\end{array}$ & $\begin{array}{l}\text { Subgroup A4 } \\
\text { Worried patients }\end{array}$ \\
\hline & $\begin{array}{l}\text { an appointment was next Monday, so in } \\
\text { a weeks' time. That's why I went to the } \\
\text { ED" (P1R). } \\
\text { "Well, I've got a problem with my eyes, } \\
\text { my skin, my scalp and it got worse the } \\
\text { last few days, so I called five } \\
\text { dermatologists today, but it's not } \\
\text { possible to see one without a date (...) } \\
\text { This problem isn't new to me, it's for } \\
\text { some time" (P37U). }\end{array}$ & & \\
\hline \multicolumn{4}{|l|}{ (C) Pathway C: referral by the outpatient provider } \\
\hline Subgroup $\mathrm{C} 1$ : reference due to time issues & $\begin{array}{l}\text { Subgroup C2: reference due to } \\
\text { challenging symptoms }\end{array}$ & & \\
\hline $\begin{array}{l}\text { "Exactly, yes, my knee is so weak. And then, today, I'd go to } \\
\text { my orthopedist, but all of them were in holidays, and the } \\
\text { substitute had too much to do, he'd said, if you have pain, go } \\
\text { to (Site I) we have too much to do, so you can have an } \\
\text { appointment in } 8 \text { days, } 8 \text { days later, and then I said: No, this } \\
\text { doesn't work. And he answered: either you go to (Site I) or } \\
\text { you have to wait until your doctor is back"' (P38U). } \\
\text { "I've called the emergency service (of the associations of } \\
\text { statutory health insurance registered doctors) and asked } \\
\text { where is the best to go. You know, my office is in X street, } \\
\text { and they suggested to go here directly" (P30U). }\end{array}$ & $\begin{array}{l}\text { "I first went to my GP and he reckoned, } \\
\text { these blood think is not ok. It's much too } \\
\text { high. Terrible. That's why I came her" } \\
\text { (P15U). } \\
\text { Participants daughter: (Mother suffers } \\
\text { from) "headaches, then we went to the } \\
\text { doctor, he said, go to the ED, that'd } \\
\text { much better" (P23U). } \\
\text { "The GP said I should go straight to } \\
\text { hospital to have it checked out because } \\
\text { they have different means than they do } \\
\text { have at the local countryside surgery" } \\
\text { (P7R). }\end{array}$ & & \\
\hline
\end{tabular}


office was closed by then. Other patients suffered from symptoms for weeks before deciding to see a physician, but then wanted immediate treatment. After failing to make an appointment on the same or following day, they went straight to the ED. Furthermore, some patients from urban regions reported dissatisfaction with their regular treatment and patients from both areas praised the ED's high medical standard and technological equipment. Hence, their motive to visit the ED was not just substitution of GP or resident specialist treatment, but also superior care. Furthermore, in cases of hesitation to see a doctor, EDs work as a convenient safety net- the availability at any time allowed the patients to delay seeking care. Meaningful quotes are presented in table 2B.

\section{Pathway C: referral by the outpatient provider}

A subgroup of patients from both regions reported that they had been referred to the ED after visiting a GP or resident specialist, either due to time constraints (Subgroup C1) or challenging symptoms (Subgroup C2) . These patients' reports indicate that the two main motives, convenience and health anxiety, also apply to this pathway, even though this was not directly assessed from the respective physicians. While some participants from urban regions reported an indifferent attitude of the GPs or Specialists they approached, patients from the rural area described purposeful reference from their GPs to the ED. Corresponding quotes are presented in table 2C.

\section{Differences between rural and urban regions}

We did not find major differences in motives for low-acuity visits to the ED between rural and urban regions, but data gave insight into the varied regional habits and practices. Nearly all interviewees from the rural region reported a strong connection to their GP, and some of these patients had been seeing their GP for decades. In contrast, many participants from urban areas were only loosely connected to a GP or did not even have one. However, interviewees from both areas used the ED purposefully in case of a subjective need for higher medical standard or time constraints. Patients from the rural site emphasised the GPs' limited diagnostic options, particularly X-ray technology. Another difference between participant groups is evident when comparing the daily curves of ED visits from urban and rural areas (figures 1 and 2). In line with the federal state slogan: 'Saxony-Anhalt-welcome to the land of early birds', times of ED visits in the rural area peak about 1 hour earlier than in urban regions. However, the time difference did not influence participants' demand for medical care.

\section{DISCUSSION}

Our findings indicate that the main motives for low-acuity ED visits are convenience and health anxiety which were reported by patients in all three possible pathways leading to an ED visit—direct visit, indirect visit after an attempt to contact a resident doctor and advice from a resident doctor to visit the ED.

\section{Convenience visits to the ED}

In our sample, the main motive for patients, who directly visited the ED without trying to make an appointment in the primary care system, were convenience reasons, addressing 24/7 hours/day accessibility and the availability of a full range of medical services. Interestingly, in this subgroup, all patients from the rural region were connected to 'their' GP, while most patients from urban regions were not or only loosely connected to any GP.

Numerous quantitative and qualitative studies from countries with good access to healthcare report that low-acuity ED visits are driven by convenience. Authors of a French study labelled their participants 'discerning health consumers', as they used the ED to profit from rapid treatment and to spare several specialists' appointments. ${ }^{11}$ A Norwegian study identified accessibility of a full range of medical services at all times as the major cause for low-acuity ED visits. ${ }^{12}$ Similarly, authors of a study on self-referred patients conducted in the Netherlands reported that the main reasons for low-acuity ED visits were faster treatment and easier access to radiological diagnostics and laboratory testing. Furthermore, patients in this study claimed that their symptoms were too severe to be treated by a GP. ${ }^{13}$ Older patients surveyed by Australian researchers aimed at timely care and fast-track access to specialist care in EDs, even though all of them were attached to a regular GP, most with timely access to office hours. ${ }^{14}$

\section{Health anxiety visits to the ED}

The second main motive for low-acuity ED visits in our study was health anxiety. Many patients who visited the ED directly or after unsuccessful attempts to approach GPs or resident specialists (group A and B) were seriously concerned about their health status. Many of these patients suffered from chronic conditions, although these were not necessarily connected to the index ED visit (figure 3). Interestingly, this finding is supported by evidence from international studies, where patients revealed fear and uncertainty as the main trigger to visit the ED. ${ }^{15-17}$ In addition, authors of international studies have shown that economically and socially deprived patients are more likely to visit ED for acute and low-acuity reasons. A lack of adequate information about their health status and limited health literacy may contribute to uncertainty and health anxiety. ${ }^{18} 19$

\section{Healthcare system-related reasons for ED usage}

Kellermann $e t a l^{20}$ have described ED usage as a "bellwether for how an overall healthcare system is functioning". Correspondingly, differences in ED usage are also caused by differences in the respective healthcare systems. A limited access to health insurance is an 
important driver for seeking low-acuity treatment in the ED. A descriptive analysis conducted in the $\mathrm{USA}^{3}$ indicated that the patterns of low-acuity ED visits vary by access to health insurance: Patients with private health insurance reported constraints related to business hours and waiting for appointments in primary care as main motives for ED visits. In contrast, the central reasons of the remaining participants were limited access to primary care caused by a lack of health insurance, income constraints and high transport costs. In Germany, where health insurance is mandatory for all citizens and all patients have access to all forms of treatment provided by the general health insurance system, these patterns and differences across patients' groups cannot be observed.

The findings of our study suggest that the strict separation between inpatientand outpatient care in the German health system affects low-acuity ED usage. In Germany, outpatient care should, by law, only be delivered by resident physicians of the outpatient healthcare system. Even though limitations in the access to outpatient care are reported as important motives for low-acuity ED visits, waiting times for consultations in Germany are relatively short compared to those in 11 other Organisation for Economic Cooperation and Development (OECD) countries. ${ }^{21}$ The number of consultations per patient is comparatively high at 17 visits annually, but the attendance time is, at an average of 7.8 min per visit, brief. $^{22}$ Additionally, the outpatient system does not manage to cover out-of-office times, even though it is obliged to reliably supply acute ambulatory care at all times. Many patients lack knowledge of the acute care facilities of the outpatient system provided in emergency practices or as mobile care structures.

Another important feature of our findings is that participants were referred by outpatient providers to visit ED with low-acuity needs. Pathway C was reported as a frequent reason in our study and is, to the best of our knowledge, not found in studies from other countries as a main cause of low-acuity ED visits. Since the German healthcare system legally requests that the outpatient service is completely covered by GPs and resident specialists, this uncovers a weakness in the division of work between the different suppliers of the German healthcare system.

Around 10 million patients visit German EDs per year (12 visits per 1000 inhabitants), ${ }^{5}$ which is still a relatively low number compared to other OECD countries (average of 31 visits per 1000 inhabitants). ${ }^{23}$ However, the annual growth rate of ED visits in Germany is, at about $5 \%,{ }^{23}{ }^{24}$ one of the highest among OECD countries. The increasing number of ED visits has caused a debate among political decisionmakers and providers of health services in Germany about the need for policy interventions in the general public and the healthcare system. Given the strict separation between inpatient and outpatient care in the German healthcare system, the current debate regarding measures to either divert patients away from EDs or to provide GP care at EDs is highly controversial between the different stakeholders. This debate overlays a discussion about the patients' underlying motives for low-acuity ED visits which needs to be taken into account when trying to implement successful solution strategies.

The findings of this as well other studies indicate that ED patients seek tailored medical help, which they do not seem to find from conventional outpatient care deliverers. Approaches to divert patients with 'inappropriate' use away from EDs do not consider patients' individual needs and expectations and may therefore remain unsuccessful.

Many participants in our study outlined a need to attend a GP or resident specialist spontaneously at regular office times as well as out-of-office times. Healthcare provision like walk-in centres in the $\mathrm{UK}^{25}$ walk-in clinics in Ireland ${ }^{26}$ or Collaborative Emergency Centers in Canada ${ }^{27}$ could address these demands for patients with minor injuries or low-acuity conditions. These centres do not provide perfect substitutes for the $\mathrm{ED},{ }^{26}$ but present suitable care for patients with low-acuity conditions. A similar approach is the provision of primary care services within or alongside hospital EDs. A Cochrane review evaluating this concept has shown disparate results, and, owing to the insufficient quality of the individual studies covered by this meta-study, the authors did not draw practical policy conclusions. ${ }^{28}$

In Germany, similar concepts are difficult to implement due to the strict separation of inpatient and outpatient care and the subsequent conflicts between healthcare providers on the funding of their services. Until now, primary care provision in German EDs has only been implemented in a few centres ${ }^{29}$ but is currently discussed to be expanded. ${ }^{30-32}$

The other main motive for seeking care in EDs was anxiety about the health status. In our sample, worried patients, of whom many were migrants, reported a lack of confidence in GP and resident specialist treatment. Intervention strategies should therefore focus on patients' trust in care providers to strengthen health literacy and adherence. A systematic review of interventions to reduce ED visits based outside EDs found the greatest reduction after patient education. ${ }^{33}$ Consequently, solutions should approach the relationship between patients and providers, particularly with respect to vulnerable patients, for example, migrants. However, in Germany, many physicians report excessive demand for their services. This is underscored by the subgroup of our interviewees who were referred to the ED by GPs or resident specialists due to time constraints. Crowded consultation hours and brief attendance time may have detrimental effects on vulnerable patients resulting in further ED visits. Some OECD countries (Canada, ${ }^{34}$ Italy, ${ }^{35}$ Australia, ${ }^{36}$ the $\mathrm{USA}^{37}$ ) developed community-based care networks, focusing on prevention and disease management to answer the demand of 
vulnerable patients and those with chronic conditions. These community health centres offer arrays of health services, providing coordinated multidisciplinary care with extended opening hours, some of them with group activities or home help hours for patients with chronic conditions. Several studies have shown that community care centres significantly decrease low-acuity visits to EDs. ${ }^{35} 37$

The implementation of multidisciplinary integrated healthcare services is also strongly recommended by policy advisors in Germany, ${ }^{38}$ especially with respect to the increasing share of elderly patients. However, these are again in conflict with the fragmented German healthcare system, where primary, secondary and tertiary care providers are funded and planned separately. ${ }^{39}$ Consequently, patient-centred integrated healthcare requires a fundamental change in the German healthcare system in order to create budgets, which cross the boundaries of primary, secondary and tertiary healthcare and provide incentives for population-related care. In the short term, measures could be undertaken for improving patients' knowledge on healthcare services which support them in finding the most appropriate place of treatment. This may include services where patients receive competent counselling per telephone in case of subjective urgent medical needs or more advanced internet-based telemedicine approaches. Nevertheless, given the increasing demand for low-acuity treatment in EDs, the EDs will require further resources in Germany in the short term to be able to provide high quality care for all patients who seek their help.

\section{Limitations}

Qualitative analysis is subjective by nature. The aim of our study was to capture a broad range of motives and attitudes for seeking care in the ED. Although measures were undertaken to reduce interview bias, it cannot be completely excluded. As such, it is possible that findings may reflect personal biases of the investigators. Even though we conducted interviews in two regions with different sample populations, the extent of variation within the study is limited and may not be generalisable to all other settings.

\section{CONCLUSION}

The main motives for visiting an ED with low-acuity conditions were convenience and health anxiety triggered by time constraints and focused usage of multidisciplinary medical care in a highly equipped setting. Although patients in the rural area are more connected to their GP, we did not find major differences in patients' motives to visit the ED. We conclude that the EDs play a pivotal role in ambulatory acute care, which needs to be recognised for adequate resource allocation. Reduction of patient numbers in the EDs requires extensive changes in the German healthcare system.
Contributors MS, JS and MM have developed the study conception and design. MS, JS, AS and JF have analysed the material. MS has written the manuscript and JS, MM and SR have given substantial input throughout the development and writing of the paper.

Funding This research received no specific grant from any funding agency in the public, commercial or non-for-profit sectors.

Competing interests None declared.

Patient consent Obtained.

Ethics approval The study was approved by the local ethics committee (Charité EA1/040/14).

Data sharing statement No additional data are available.

Open Access This is an Open Access article distributed in accordance with the Creative Commons Attribution Non Commercial (CC BY-NC 4.0) license, which permits others to distribute, remix, adapt, build upon this work noncommercially, and license their derivative works on different terms, provided the original work is properly cited and the use is non-commercial. See: http:// creativecommons.org/licenses/by-nc/4.0/

\section{REFERENCES}

1. Pines JM, Hilton JA, Weber EJ, et al. International perspectives on emergency department crowding. Acad Emerg Med 2011;18:1358-70

2. Epstein SK, Huckins DS, Liu SW, et al. Emergency department crowding and risk of preventable medical errors. Intern Emerg Med 2012;7:173-80.

3. Hefner JL, Wexler R, McAlearney AS. Primary care access barriers as reported by nonurgent emergency department users: implications for the US primary care infrastructure. Am J Med Qual 2015;30:135-40.

4. Steffen W, Tempka A, Klute G. Unhelpful incentives in hospital emergency departments. Dtsch Arztebl 2007;104:A-1088-91.

5. Haas Ch. Larbig M, Schöpke T, Lübke-Naberhaus KD, et al. Gutachten zur ambulanten Notfallversorgung intramuscular Krankenhaus. 2015. http://www.dgina.de/media/press/2015-02-17 Gutachten_zur_ambulanten_Notfallversorgung_intramuscular_ Krankenhaus_2015.pdf

6. Brachmann M, Geppert R, Niehues C, et al. Ökonomische Aspekte der klinischen Notfallversorgung. Deutsche Gesellschaft interdisziplinäre Notfall- und Akutmedizin e.V. DGINA

Positionspapier der AG Ökonomie 2012. http://www.dgina.de/media/ download_gallery/DGINA_Positionspapier_Ökonomische_Aspekte_ klinische Notfallversorgung 2009.pdf

7. Choo EK, Garro AC, Ranney ML, et al. Qualitative research in emergency care part I: research principles and common applications. Acad Emerg Med 2015;22:1096-102.

8. Ranney ML, Meisel ZF, Choo EK, et al. Interview-based qualitative research in emergency care part ii: data collection, analysis and results reporting. Acad Emerg Med 2015;22:1103-12.

9. Schmiedhofer $\mathrm{MH}$, Searle J, Slagman A, et al. Inanspruchnahme zentraler Notaufnahmen: qualitative Erhebung der Motivation von Patientinnen und Patienten mit nichtdringlichem Behandlungsbedarf. Exploring Patient Motives to Use Emergency Department for Non-urgent Conditions: a Qualitative Study. Gesundheitswesen 2016;doi:10.1055/s-0042.100729.

10. Meier M. Qualitative content analysis in practice. London: SAGE, 2012. https://uk.sagepub.com/en-gb/eur/qualitative-content-analysisin-practice/book234633

11. Durand AC, Palazzolo S, Tanti-Hardouin N, et al. Nonurgent patients in emergency departments: rational or irresponsible consumers? Perceptions of professionals and patients. BMC Res Notes 2012;5:525.

12. Ruud SE, Hjortdahl P, Natvig B. It is a matter of urgency? A survey of assessments by walk-in patients and doctors of the urgency level of their encounters at a general emergency outpatient clinic in Oslo, Norway. BMC Emerg Med 2016;16:22.

13. Kraaijvanger N, Rijpsma $D$, van Leeuwen $H$, et al. Self-referrals in the emergency department: reasons why patients attend the emergency department without consulting a general practitioner first-a questionnaire study. Int $J$ Emerg Med 2015:8:46

14. Lowthian JA, Smith C, Stoelwinder JU, et al. Why older patients of lower clinical urgency choose to attend the emergency department. Int Med J 2013;43:59-65. Royal Australasian College of Physicians. 
15. Lawson CC, Carroll K, Gonzales R, et al. "No other Choice". Reasons for emergency department utilization among urban adults with acute asthma. Acad Emerg Med 2014;21:1-8.

16. Rising KL, Hudgins $A$, Reigle $M$, et al. I'm just a patient: fear and uncertainty as drivers of emergency department use in patients with chronic disease. Ann Emerg Med 2016;68:536-43. Online publication 2016

17. Delea S, Buckley C, Hanrahan A, et al. Management of diabetic foot disease and amputation in the Irish health system: a qualitative study of patients' attitudes and experiences with health services. BMC Health Services Res 2015;15:251. http://bmchealthservres. biomedcentral.com/articles/10.1186/s12913-015-0926-9

18. VanStone NA, Belanger $\mathrm{P}$, Moore $\mathrm{K}$, et al. Socioeconomic composition of low-acuity emergency department users in Ontario. Can Fam Physician 2014;60:355-62.

19. Mahmoud I, Hou X. Immigrants and the utilization of hospital emergency departments. World J Emerg Med 2012;3:245-50.

20. Kellermann AL, Martinez R. The ER, 50 years on. N Engl J Med 2011;364:2278-9.

21. Osborn R, Schoen C. The Commonwealth Fund 2013 International Health Policy Survey in Eleven Countries. 2013. http://www.commonwealthfund.org/ /media/files/publications/ in-the-literature/2013/nov/pdf_schoen_2013 inp_survey chartpack_final.pdf

22. Grobe TG, Dörning H, Schwartz FW. BARMER GEK Arztreport Band 1. St. Augustin 2010. https://www.barmer-gek.de/barmer/web/ Portale/Veorts/PDF__Arztreport,property=Data.pdf

23. Berchet C. "Emergency Care Services: Trends, Drivers and Interventions to Manage the Demand", OECD Health Working Papers, No. 83. Paris: OECD Publishing, 2015.

24. Zentralinstitut für die Kassenärztliche Versorgung in Deutschland. Zl-Analyse der Notfallbehandlungen 2009-2014. http://www.zi.de/ $\mathrm{cms} /$ ileadmin/pdf/Anlage_Analyse_der_Notfallbehandlungen.pdf

25. Gov. UK. Walk-in centre review: final report and recommendation. 19. 2014. https://www.gov.uk/government/publications/ nhs-walk-in-centre-services-in-england-review

26. Government of Ireland. Report of the Comptroller and Auditor General. Emergency Departments, 2009. http://www.audgen.gov.ie/ documents/vfmreports/70_Emergency_Departments.pdf

27. Department of Health \& Wellness/Health PEI Canada. http://www. healthpei.ca/walkinclinics

28. Tan S, Mays N. Impact of initiatives to improve access to, and choice of, primary and urgent care in England: a systematic review. Health Policy 2014;118:304-15.
29. Khangura JK, Flodgren G, Perera R, et al. Primary care professionals providing non-urgent care in hospital emergency departments. Cochrane Database Syst Rev 2012;11:CD002097.

30. Schleef T, Schneider N, Tecklenburg A, et al. Allgemeinmedizin in einer universitären Notaufnahme-Konzept, Umsetzung und Evaluation. General Practice in a University Emergency Department -Concept, Implementation and Evaluation. Gesundheitswesen 2016;doi:10.1055/s-0042-100730.

31. Gesetz zur Reform der Strukturen der Krankenhausversorgung. Krankenhausstrukturgesetz-KHSG. Bundesgesetzblatt 12/17/2015 Part I No. 51. http://www.bmg.bund.de/themen/krankenversicherung/ krankenhausstrukturgesetz/khsg.html

32. Köster C, Wrede S, Herrmann T, et al. Ambulante Notfallversorgung Analyse und Handlungsempfehlungen. Göttingen: AQUA-Institut für angewandte Qualitätsförderung und Forschung intramuscular Gesundheitswesen $\mathrm{GmbH}$, 2016. http://www.aqua-institut.de/aqua/ upload/CONTENT/Projekte/eval_forsch/Gutachten_ Notfallversorgung.pdf

33. Morgan SR, Chang AM, Alquatari M, et al. Non-emergency department interventions to reduce ED utilization: a systematic review. Acad Emerg Med 2013;20:969-85.

34. Department of Health and Wellness Novascotia Canada. http:// novascotia.ca/dhw/primaryhealthcare/CEC.asp

35. Bruni ML, Mammi I, Ugolini Ch. Does the extension of primary care practice opening hours reduce the use of emergency services? Department of Economics, University of Bologna, 2014. http://www2. dse.unibo.it/wp/WP978.pdf

36. Australien Government. The Department of Health. http://www. health.gov.au/internet/main/publishing.nsf/Content/ pacd-gpsuperclinic-about

37. Choudhry L, Douglass M, Lewis J, et al. The impact of community health centers \& community-affiliated health plans on emergency department use. National Association of Community Health Centers, 2007. http://www.nachc.com/client/ACAPReport.pdf

38. ADVISORY COUNCIL on the Assessment of Developments in the Healthcare System. Needs-based Healthcare: Opportunities for Rural Regions and Selected Healthcare Sectors 2014. http://www. svr-gesundheit.de/fileadmin/user_upload/Gutachten/2014/ SVR-Gutachten_2014_Kurzfassung_engl.pdf

39. ADVISORY COUNCIL on the Assessment of Developments in the Healthcare System. Competition at the Interfaces between inpatient and outpatient Healthcare Special Report. http://www.svr-gesundheit. de/fileadmin/user_upload/Gutachten/2012/Kurzfassung-eng_ formatiert.pdf 